Legislación utilizada.

- Constitución política de la República de El Salvador 1962, San Salvador, Diario Oficial № 10, Tomo: 194.

Amaral Palevi Gómez Arévalo

Experiencia laboral en la ejecución de proyectos de desarrollo, en los cargos de técnico en salud y masculinidad; coordinador municipal de Comunidades Solidarias Rurales; técnico en alfabetización de adultos, habilitación laboral y educación inicial comunitaria. Experiencia docente como auxiliar de cátedra en la Universidad de E Salvador. Actualmente estudiante del programa de Doctorado Oficial en Estudios de Paz, Conflictos y Desarrollo de la Universitat Jaume I.

\section{EMPODERAMIENTO Y \\ RESPONSABILIDAD DE LA \\ CULTURA PARA LA PAZ \\ A TRAVÉS DE LA \\ EDUCACIÓN}

Mariela Inés Sánchez Cardona

marielainesanchez@hotmail.com

\section{Resumen}

Ee presente artículo pretende dar a conocer las posibilidades de empoderar la cultura para la paz en la sociedad en general, para ello se hace necesario de un trabajo mancomunado de diferentes actores e instituciones sociales. En esta perspectiva cada individuo debe transcender del compromiso con la paz de lo personal a lo social, asimismo el Estado específicamente en el caso de Colombia debe vigilar por el cumplimiento de la normativa en cuento a la obligatoriedad de la educación para la paz en las instituciones educativa a través de políticas públicas. Del mismo modo, se enfatiza que cuando se logra desarrollar coherentemente los principios y metodologías de la educación para la paz, en las instituciones tanto familiares, escolares y universitarias, ello facilita el fortalecimiento de la cultura para la paz en país determinado.

Palavras-chave: Cultura de paz, Políticas Públicas, Educación para la paz, Instituciones Educativas, Actores de cambio, Reconocimiento, Familia, Responsabilidad.

\section{Abstrac}

This article seeks to highlight the possibilities of empowering the culture of peace in the society in general, so it is necessary a joint work of different actors and social institutions. In this perspective each individual must transcend commitment to the peace of the personal to the social, also the State specifically 
in the case of Colombia must be monitored for compliance with the legislation in story to the compulsory education for educational institutions peace through public policies. Similarly, we emphasize that when they achieve consistently develop the principles and methodologies of education for peace, in institutions both family, school and University, this facilitates the strengthening of the culture for peace in the country.

Keywords: Culture of Peace, Public Policy, Peace Education, Educational Institutions, Actors change, Recognition, Family, Responsibility

\section{INTRODUCCIÓN}

- Iartículo intenta analizar que el tema de la responsabilidad y fortalecimiento - de la cultura para la paz en una nación determinada, es un compromiso que debe realizar varias personas e instituciones a diferentes niveles. El tema se desarrolla en cuatro capítulos, en el primero, se hacen delineamientos teóricos de lo es la cultura para la paz, seguido del segundo donde se introduce el tema de la educación para la paz como una forma desarrollar dicha cultura. En el tercero se plantea los objetivos y pretensiones propiamente dicha de la educación para la paz y por último, en el cuarto capítulo, se desarrolla el tema de los niveles de responsabilidad que tienen las personas e instituciones en el quehacer de la paz a saber: el individuo mismo, el Estado, los colegios, la familia y las universidades en general.

\section{Aproximaciones teóricas de la cultura de la paz}

Se puede afirmar que la paz no sólo es posible, sino que es necesaria y vital para la sociedad, y se puede construir desde diferentes rutas y ritmos (Fisas, 2002: 17). Podría pensarse que se puede concebir en distintos niveles: a nivel personal a través del cambio de actitudes; a nivel social, por un perfil de colectividad; a nivel político-jurídico por medio de la sensibilización de los Estados y a un nivel internacional (Burguet Arfelis, 1999: 14-15). El filósofo italiano Norberto Bobbio plantea como una necesidad urgente, fundamentar la paz en una pedagogía que trabaje el esfuerzo, donde los resultados no se dan a corto plazo y se amerita el compromiso de cada ser humano (Bobbio, 1966: 49). Puesto que la paz es algo que se debe asumir con una voluntad dinámica, todo el mundo puede pensar en ella y aportar en su construcción.
Por lo tanto se debe analizar la cultura de paz como un proceso que exige de la participación universal desde la investigación y la práctica, es un asunto que no debe dejarse sólo en manos de los políticos, líderes sociales o colegios. Ya desde 1995 la Organización de las Naciones Unidas para la Educación, la Ciencia y la Cultura (UNESCO) ha hecho un pronunciamiento frente al tema y enfatiza en la importancia de atacar las raíces de los conflictos sociales, como una medio para facilitar la cultura de paz, entendida no como mera ausencia de guerra, sino un compromiso y una práctica de todos, cuyo objetivo es construir una sociedad justa, equitativa, solidaria y pluralista, a través de la implementación eficaz de reformas sociales(UNESCO,1995:8).

Otros autores como Vicent Fisas, plantea que para pasar de una cultura de la violencia a una cultura de paz, se hace necesario entender en primer lugar, que la violencia es un ejercicio de poder que excluye otras formas de afrontar los conflictos, por lo que se requiere de un conjunto de estrategias alternativas que permitan sustituir el poder ciego por un tipo de autoridad que evoque respeto, asociada al amor, la vida y la gratitud. A través de esta vía se llega a una negociación colaborativa y a una mediación razonable, que sirven de pilares fundamentales de la cultura de paz (Fisas, 2002: 63-64).

Investigadores como Jares, hacen sus aportes al respecto enfatizando en el deber que cada ciudadano tiene en la búsqueda de soluciones a los conflictos existentes en cada nación. Estos planteamientos empoderan a los individuos en la consecución de la paz y no dejan el compromiso sólo a los actores políticos, al tiempo que expresan cómo la cultura de paz se asienta en el debate, en la crítica, en el diálogo y en la libertad de expresión. En esta dirección se debe recuperar para muchos ciudadanos, el valor del compromiso y la solidaridad frente a la cultura de la indiferencia y el menosprecio. Estos cimientos tienen el valor de posibilitar a cada uno, la capacidad de aprender a compartir, a cooperar, a ser solidario y feliz (Jares, 2003: 100). Este mismo enfoque es compartido por Tuvilla Rayo, quien afirma que para construir paz, es necesario trabajar en el respeto de los derechos humanos y en el fortalecimiento de la democracia y la sociedad civil (Tuvilla Rayo, 2004a: 33). Así mismo la cultura de la paz está basada en el reconocimiento de cada ser humano con principios de igualdad, justicia y equidad donde haya espacio para la expresión de sentimientos de ternura entre los pueblos (Jares, 2001: 119-123).

La paz se podrá alcanzar en el esfuerzo mancomunado de la sociedad, en el 
caso del Estado tendría que actuar por medio de las constituciones políticas en el cual se conciba la paz como un valor universal que sirva para construir la armonía social donde prevalezca el respeto por cada individuo en particular. Vale la pena anotar que las concepciones de cultura de paz que se retoman en este apartado, coinciden con algunos autores en cuanto a que ella se construye en la cotidianidad, y constituye un mandato objetivo para cada ser humano (Martínez Guzmán, 2005; Comins Mingol, 2009; Jalali Rabbani, 2001; Tuvilla Rayo, 2004a - b). Teniendo en cuento los anteriores postulados, es indiscutible que para que este pensamiento se vuelva realidad, es necesario los fundamentos teóricos/ prácticos de la educación, la cual aportaría con metodologías plausibles para instaurar y legitimar la paz en la humanidad (Montessori, 2003: 49, 62; Manjarrés y Molano, 2001: 30).

A modo de resumen se quiere formular que la Cultura de la paz, pretende en última instancia regir las actuaciones sociales de los sujetos, orientándolos hacia la construcción de una sociedad más justa, solidaria y pluralista, con el propósito de eliminar las raíces de la violencia a través de estrategias de paz. En particular Colombia necesita el compromiso de todos y cada uno, con el ánimo de implementar metodologías centradas en la Educación para la paz, que logren jalonar una paz duradera y sostenible en la sociedad en general y, que al mismo tiempo, sirvan para contrarrestar los grandes y graves efectos de la violencia estructural que se vive en el país. Por ello en el siguiente acápite se desea profundizar un poco más acerca de los objetivos y pretensiones que sustentan la Educación para la Paz.

\section{La cultura de Paz a través de la Educación para la Paz}

De una manera clara se quiere plantear que la Educación para Paz, es uno de los tantos caminos que se deben recorrer en Colombia para cimentar la verdadera cultura de la paz. Sin embargo es importante aclarar, que esta necesidad de paz no es sólo de este país, ya que es una prioridad de todo el mundo y no exclusivamente de Latinoamérica. El reconocimiento y confirmación de esta prioridad mundial, es vital para entender que ciertos países primero, no están solos en la búsqueda de la paz y segundo, que a pesar de que las estructuras de violencia se encuentran probablemente menos visibles en algunas naciones, son exactamente ellas las que tienen una mayor responsabilidad y deben brindar más luces a "otras" naciones que en ocasiones han perdido su sendero de paz, o a veces no encuentran salidas a las encrucijadas de violencia que viven a diario.

La mirada planteada en el anterior parágrafo, en cuanto a la necesidad de un compromiso universal para el quehacer de la paz, debe apuntar hacia una ética mundial, que permita construir una visión realista del futuro para cada nación en el contexto global. A pesar de que este artículo enfatiza en la educación como un medio para instaurar la paz en el planeta, sin embargo se debe hacer precisión de la importancia de desarrollar otras metodologías desde la ética, la política, la economía, la ecología, las comunicaciones en busca de mejorar el desarrollo integral del ser humano. Dicho pensamiento, lo ha venido liderando entre otros, el teólogo Hans Küng y algunas de sus ideas se han cristalizado en un documento publicado en 1993, respaldado por la ONU, que lleva por título “Declaración de una Ética Mundial” (Rojas Claros, 2008: 149-151). Cabe anotar que lo escrito en dicho documento, puede en parte hacerse realidad a través de la contribución teórica concebida por Jalali Rabbani (2001) en materia de educación para la ciudadanía mundial, cuyos planeamientos giran en torno al reconocimiento del individuo mediante principios de igualdad e interdependencia, como una precondición para la expresión de la plena libertad del ser humano (Jalali Rabbani, 2001: 53). A continuación de manera más explícita se desea plasmar los objetivos propiamente dichos que persigue la educación para la paz en aras de empoderan una verdadera cultura del la tolerancia y respeto entre los individuos.

\section{Objetivos y pretensiones de la educación para la Paz}

La principal presunción que respalda la educación para la paz es que si los ciudadanos poseen más información acerca de las alternativas frente al uso de la fuerza, rechazarán siempre los caminos de la violencia. Esta educación, como una estrategia para una paz duradera, se fundamenta en la formación de los individuos con el fin de que sirvan de gran apoyo a las políticas pacíficas de cada nación. Del mismo modo aspira a que la constante preocupación por la paz, tenga enorme acogida a través de toda la sociedad, y se convierta en una norma que guíe la conducta humana. Con estos planteamientos se quiere lograr que en el futuro, las personas promotoras de paz, sean cada vez más y, de esta forma, que pueden promover y empoderar la paz en las sociedades, inclusive con mayor protagonismo que los gobiernos, ya que la gente desea tanto la paz, que un buen día los gobiernos tendrán que abandonar sus formas de hacer la paz para permitirle a la sociedad elegir las suyas (Harris, 1988: 13). 
La tarea que asume la educación para la paz, es plantear de forma concreta una sociedad pacífica y justa, que respete los derechos humanos y proteja el medio ambiente, así mismo, que eduque a los individuos para lograr y mantener un orden coherente con esta forma de sociedad (Reardon and Eva Nordland, 1994: 24). Uno de los aportes más valiosos se orientan a la prevención de comportamientos negativos, tanto individuales como grupales, que son capaces de deteriorar la convivencia pacífica a nivel individual, social y ecológico. Esta perspectiva proactiva de prevención, realiza apreciables contribuciones encaminadas a reafirmar y fomentar los procesos de paz en todos los escenarios. Podría hacerse un símil de los planteamientos filosóficos que se abordan desde la educación para la paz, con la medicina en general, campo en el cual se ha impulsado durante los últimos años, un enfoque preventivo de las enfermedades físicas y psicológicas.

La educación para la paz promueve no solamente el deseo de paz que subyace en la mente humana, sino que también enseña habilidades para construir la paz (Crews, 2002) y para que los seres humanos puedan aprender formas no violentas que ayuden a mejorar la interacción con los demás. De igual forma dicha teoría busca confrontar y condenar de manera directa, cualquier clase de violencia que predomine en las sociedades, mediante lineamientos filosóficos que apuntan a desarrollar una conciencia pacífica que garantice la transformación de los conflictos (Danesh, 1979), a través del uso de herramientas de paz entre las personas, y que ofrezca una solución de largo plazo frente a las amenazas inmediatas de la guerra. Por lo tanto la principal estrategia que se plantea, es educar a millones de estudiantes, quienes deben a su vez trabajar para cambiar sus comportamientos violentos (Harris, 1988: 6-14).

Las metodologías de paz contribuyen en todas las áreas del desarrollo infantil a nivel físico, cognitivo, social y emocional. De esta manera, al formarse en la importancia de vivenciar la paz en la experiencia de vida, los niños ganan confianza en el desarrollo de sus destrezas, y de esta manera logran el éxito en sus tareas, obteniendo resultados satisfactorios para sí mismos y en la convivencia con los demás (Noddings, 2005). De otro lado, a través de la utilización de herramientas pacíficas, los adultos pueden ayudar a la juventud a abordar sus problemas y a resolverlos apaciblemente, empleando por ejemplo, técnicas de negociación y dinámicas de comunicación adecuadas, que les permita estimular la expresión de las emociones e interpretar el lenguaje no verbal de sus conductas. Dicho aprendizaje es de gran importancia en la preparación de los jóvenes para la paz (Mayor, 1996: 109).

En esta investigación se acoge al planteamiento de Harris en el que se argumenta que es necesario romper ciertas estructuras mentales creadas por muchos años frente al tema de la guerra. Teniendo en cuenta las experiencias de docencia en educación para la paz tanto a nivel formal como informal, se puede concluir que el cambio de paradigmas y el trabajo en pos de crear nuevas formas de pensar, son tareas arduas. Los aportes de la psicología cognitiva, han demostrado que es mucho más fácil para el individuo conservar las viejas ideas que cambiarlas. Los seres humanos necesitan cierto grado de seguridad que les brinda los pensamientos antiguos, por consiguiente imaginar nuevos modelos de pensamiento, genera miedo en los individuos, ya que constituyen una amenaza para los sentimientos de control personal y la seguridad emocional. Por consiguiente los procesos pedagógicos que apunten a enseñar metodologías para sentir la paz, romper paradigmas e ir más allá de lo teórico, para influir en el estilo de vida de las personas y los valores culturales de una población, requieren tiempo, paciencia y especialmente tolerancia en países como Colombia.

En particular se ha encontrado, que aunque los estudiantes traten de interiorizar cómo pueden llegar a transformar los conflictos a través de herramientas de no violencia, al llegar a sus casas se encuentran con una realidad muy diferente, pues muchos viven diariamente formas de violencia estructural. Por lo tanto, esos estudiantes pueden concluir que la transformación del conflicto desde la teoría de la paz, no se compagina con su vida diaria y en fin, resulta poco viable.

El papel de los educadores de paz consiste es ayudar a los estudiantes a analizar las contradicciones de cada sociedad, a través de una metodología racional que les permita comprender mejor un futuro de paz. También es muy útil que sientan que no están solos en este proceso, y que alguien está escuchando sus contradicciones. A menudo, tan solo existe un lugar en donde pueden transformar sus conflictos personales, y fortalecer sus esperanza e ideales de paz y éste es la escuela, ya que en sus hogares y en la sociedad en general, perciben mucha violencia y las estructuras sociales inequitativas terminan por oprimir sus ideas de paz.

La ventaja de la educación para la paz y de la investigación sobre la paz, es que nos permite mantener una actitud crítica ante las estructuras sociales y usar los cerebros e imaginación, en la búsqueda de alternativas; 
así que, cuando lleguen las oportunidades, y es seguro que llegarán, podremos aprovecharlas (Harris, 1988: 15).

En la sociedad colombiana trabajar con los conflictos personales de los seres humanos es algunas veces más satisfactorio que trabajar con los escenarios de violencia estructural. De acuerdo a experiencias en el campo de la psicología, se observa que en todos los casos el individuo desea tener paz interior. En un comienzo, puede ser un poco difícil motivar esta clase de cambio personal, pero a través de procesos de interiorización y de reflexión, el individuo puede percatarse de las ventajas de sentir paz y de expandirla en todos los escenarios de vida. En cambio, al trabajar en programas educativos direccionados a la reducción de la violencia estructural es un común denominador, la intervención es más problemática, las personas tienden a ser escépticas hacia la teoría de la paz y tienden a interpretar y a utilizar métodos de guerra para conseguir la paz; de igual forma es más evidente el interés por el poder, la reputación y el dinero. Esta situación se reitera especialmente en los grupos de políticos, alcaldes y/o líderes sindicales.

Educar para la paz es un proyecto global y multidisciplinario que concierne a todas las áreas del currículo educativo, y se encuentra cimentado en los conceptos de paz positiva y conflicto; se mueve desde lo didáctico y a través de la construcción de relaciones de paz entre los integrantes de la clase, ampliándose a la comunidad que conforma el centro educativo $y$, posteriormente, a la sociedad que la rodea. El desafío es fundar el proceso educativo a partir de unas relaciones de paz, lo cual se define como un objetivo educativo en sí mismo, y a la vez, como un requerimiento metodológico y organizativo que beneficia los procesos de enseñanza-aprendizaje (Jares, 2003: 87).

Uno de los autores que mejor ha resumido las principales metas de la educación para la paz, es el investigador lan Harris $(1988,2002)^{1}$ quien las agrupa en diez metas que a continuación se presentan:

1. Apreciar la riqueza del concepto de paz. La educación para la paz proporciona en las mentes de los estudiantes una visión dinámica de la paz que contrarresta las imágenes violentas que dominan la cultura.

2. Abordar los temores. Los educadores de paz abordan los temores de las gentes ante la aparente imposibilidad vivir en armonía.

3. Proporcionar información acerca de los sistemas de defensa. Los ciudadanos necesitan información acerca de los diferentes sistemas de

1Traducción realizada por la autora defensa que posee cada nación. Por ejemplo, ejércitos y armadas navales para suministrar protección contra posibles ataques.

4. Comprender el comportamiento de la guerra. Los estudiantes en las clases de educación para la paz estudian las causas principales de la injusticia, la violencia, y de la guerra.

5. Desarrollar una comprensión intercultural. Los estudios de paz se enfocan en la forma en que las instituciones humanas manejan los conflictos de orden internacional, así como también enseñan cómo se originaron tales conflictos.

6. Proporcionar una orientación para el futuro. Los estudiantes y maestros en las clases de estudios para la paz, visualizan cómo podría ser el futuro y luego discuten lo que puede hacerse para lograr la paz. Para autores como Jares (1994), «Educar para la paz no es educar para la inhibición de la agresividad, sino para su afirmación y canalización hacia actividades socialmente útiles» (Jares, 1994:290).

7. Enseñar la paz como un proceso. La educación para la paz también proporciona habilidades para moverse en el mundo lejos de la violencia, y a la vez estimula este cambio de manera precisa y puntual en el individuo.

8. Promover un concepto de paz que vaya acompañado de la justicia social, puesto que la lucha por la paz abarca la justicia; por ello los estudiantes de educación para la paz, deberán aprender sobre los problemas de los derechos humanos, pues como lo plantea Jares (1994):

Educar para la paz supone educar desde y para unos determinados valores, tales como la justicia, la cooperación, la solidaridad, el desarrollo de la autonomía personal y la toma de decisiones, etc., al mismo tiempo que se cuestionan aquellos que son antitéticos a la cultura de la paz, como son la discriminación, la intolerancia, el etnocentrismo, la obediencia ciega, la indiferencia e insolidaridad, el conformismo, etc. (Jares, 1994: 289-290

Los educadores de la paz enseñan acerca de los problemas que incuban la injusticia, y usan este conocimiento para empoderar a los demás.

9. Estimular el respeto por la vida. El logro de la paz representa un proceso de humanización mediante el cual los individuos superan sus tendencias violentas; por ende la educación para la paz, enseña a tener respeto por la vida. Es necesario entonces que los estudiantes de paz desarrollen imágenes positivas de ellos mismos, con un sentido de responsabilidad hacía sí mismos y los demás, y con una capacidad de confiar en los otros. 
10. La última meta de la educación para la paz, es abordar los problemas creados en un mundo consumido por los comportamientos violentos. Para ello los estudiantes de educación para la paz, deberán aprender cómo resolver disputas de manera no violenta y a hacer del mundo un lugar más seguro, ya que la humanidad no podrá alcanzar su pleno potencial sino hasta que la violencia se haya detenido (Harris, 1988: 17-20; 2002: 20).

Este pensamiento también ha sido liderado por la investigadora del tema educación para la paz, Betty Reardon (1988), quien plantea que esta educación pretende integrar al individuo con la sociedad y con su entorno natural. Una educación, sin esta cuidadosa consideración de las interrelaciones en los niveles de la organización social y el entorno natural para el desarrollo de la persona humana, no podrá formar una auténtica integridad y conexión con el mundo (Reardon, 1988: 58). Este argumento apunta directamente a buscar una educación holística donde el ser humano es el centro de la educación, tesis igualmente compartida por otros autores como Desidero de Paz Abril (2007) Francisco Jiménez Bautista (2004).

Sin embargo, lograr las metas y objetivos previamente expuestos, no es una tarea fácil, por el contrario, constituye un gran reto para todo el mundo. Podría pensarse que es un trabajo trascendental y crucial, a pesar de que en muchas ocasiones resulte agotador, aunque finalmente gratificante. Es así como el papel de los educadores es fundamental, ya que aquellos ayudarán a desarrollar visiones plausibles de paz dentro de las aulas de clases, que ofrezcan alternativas frente al comportamiento violento. Por otro lado Alfonso Fernández (2000), profesor de la Universidad de Granada, plantea como un reto de la educación para la paz, la transversalidad de las diferentes dimensiones de la paz (personal, social y ecológica), es decir que el compromiso de estas disciplinas sociales con la paz, debe llevar no solo a contemplarla como un objetivo, sino también a implementarla como una práctica que sea compatible en la Cultura de la Paz, tanto al interior de las aulas, como fuera de ellas (Fernández Herrería, 2000: 114).

Se puede perfectamente deducir, que hacer realidad estos objetivos de la educación para la paz anteriormente plasmados no es fácil y es un cometido de todos los individuos y diversas instituciones en cada país. Para el caso específico de Colombia en el siguiente y último apartado de este artículo se quiere analizar más específicamente las diferentes instituciones y niveles que tienen responsabilidad en el quehacer de la cultura para la paz en este país.

\section{Niveles de responsabilidad de la educación para la paz}

4.1 De lo personal a lo colectivo

Uno de los problemas actuales para que la paz en el planeta sea duradera, consiste en la falta de compromiso y responsabilidad de muchas personas en hacer realidad este deseo. De una manera muy especial, se observa con frecuencia, que cuando se educa a los adultos en estos temas, aparece en muchas ocasiones automáticamente una resistencia, ya que el cambio de ciertas actitudes y comportamientos en el individuo puede resultar incómodo, y exige un esfuerzo mental que permita su transformación. Esta resistencia podría obedecer al hecho de que por mucho tiempo, las personas han introyectado ciertas concepciones erradas de lo que implica el fenómeno de la responsabilidad en la construcción de una sociedad pacifica. De una manera muy precisa todavía se sigue pensando, que sólo se tiene un compromiso de colaboración con aquellas personas que tienen cierto grado de cercanía familiar o de amistad, mientras que el sufrimiento de los otros se suele ignorar, o se deja en manos del Estado o el Gobierno de turno.

Al respecto la investigadora Irene Mingol de la Universidad Jaume I, en su libro Filosofía de Cuidar plantea, entre otras, como una propuesta de educación para la Paz que la ética de cuidar «debe extenderse más allá del ámbito privado para abarcar lo global» continúa exponiendo que esta ética acentúa interés por los grupos más desprotegidos (Comings Mingol, 2009: 91-104). Esta tesis tiene cierta concordancia con los planteamientos de la investigadora Martha Jalali, cuando esboza que para facilitar el proceso de inclusión del otro se debe pensar en el concepto de amigo universal para que incluso las relaciones de reconocimientos más locales y familiares sean significativas. La autora hace un llamado de atención a la aceptación de manera incondicional del otro sin hacer distinciones ni limitar la inclusión a las personas que son miembros de otra comunidad y poseen diferentes valores culturales (Jalali Rabbani, 2009:102).

Esta forma de pensar que incluya la responsabilidad que se tiene con los otros independiente de las relaciones de familiares y amistad selectiva, puede cambiarse más fácilmente en los niños, ya que se encuentran en etapas tempranas de la formación de su personalidad. Una intervención temprana permitirá fortalecer su responsabilidad en el compromiso social con la paz, cuando lleguen a la edad adulta.

En este largo camino, de nuevo aparece la educación como una herramienta 
que permitirá jalonar este proceso dentro de la sociedad, pues con ella se busca «\{...\} proporcionar elementos a niños, niñas y jóvenes para que puedan comprometerse, transformar y mejorar el mundo"(Paz Abril, 2007: 17). Siguiendo los lineamientos de la psicoterapeuta y experta en educación del carácter en las escuelas, Linda Kavelin Popov, la meta es utilizar la autoridad en contextos escolares con el fin de facilitar en el niño, el desarrollo de su propia autoridad interior y un sentido de responsabilidad personal que lo habilite para tomar conscientemente decisiones morales coherentes en diversos contextos sociales (Kavelin Popov, 2000: 58).

Una educación para la paz debe partir de un reconocimiento explícito de la importancia de formar personas conscientes de su rol y responsabilidad con el mundo, lo que implica el desarrollo de una ciudadanía participativa en la construcción de la convivencia social. Lo anterior requiere de un proyecto pedagógico basado en una metodología incluyente que promueva los derechos humanos y el respeto de la diversidad religiosa, ideológica y cultural (Tuvilla Rayo, 2004a: 139-140, 222, 229, 236).

En el sistema educativo, la formación en el principio de la responsabilidad de crear armonía en la humanidad, debería ser un eje transversal en el currículo escolar, ya que una persona responsable entiende que pertenece a múltiples grupos, colectividades o comunidades diversas dentro de la sociedad, la nación, y finalmente, la humanidad misma. Dicha virtud favorece la conciencia personal de una profunda interconexión con los demás, como una precondición para el desarrollo de una vida saludable.

El concepto de responsabilidad social va conectado con los conceptos de libertad y libre albedrío. Un individuo responsable es libre, lo cual significa que no solamente es libre para hacer lo que elija sino también para pensar y actuar de una manera constructiva, incluso auto-restrictiva, cuando sea necesario. En relación con este tema, vemos como en la sociedad colombiana muchas personas tienen una comprensión errada del significado de libertad. Creen que pueden destruir a otros seres humanos, y no establecen una relación entre la libertad y la responsabilidad social; están perdiendo el respeto y la sensibilidad por el sufrimiento ajeno; entienden de manera equivocada el concepto de libertad, creyendo que ésta significa independencia absoluta de la sociedad; han perdido el concepto de unidad, entendido en su visión holística del mundo y finalmente, observamos también cómo se ha deteriorado el principio de interdependencia.
Ya desde 1970, Hans Reiss ha concebido este tema a un nivel de derecho universal de la humanidad el cual plantea que «La gente en la tierra ha entrado en gran codependencia con la comunidad universal, y ésta se ha desarrollado hasta el punto en que una violación de los derechos humanos en una parte del mundo, es sentida en todas partes» (Reiss, 1970: 107)' ${ }^{1}$. Dicha tesis también es compartida por Carol Gilligan, cuando plantea que el individuo tiene una responsabilidad hacia el mundo cuyo objetivo no es sólo vivir para obtener placer, sino que también se tiene la obligación moral de contribuir a que en el mundo se viva mejor (Gilligan, 1986: 45).

En otras palabras, ser socialmente responsable significa estar listo para transformar la realidad, de acuerdo con valores universales, pero en situaciones concretas; por consiguiente, la responsabilidad no sólo debe existir de manera abstracta y teórica, sino que debe manifestarse en las acciones a nivel personal, local (familiar, comunitario) y global (ciudad, país, mundo); por consiguiente, es importante pensar y actuar en el marco de unas posibilidades de acción responsable, aprovechando todas las oportunidades que existan para tal comportamiento. De otro lado, sería equivocado considerar que el pensamiento responsable, está siempre centrado en los problemas globales. Una persona responsable no puede ignorar los problemas globales, pero no puede tampoco darles una prioridad absoluta. Comenzar a pensar en la paz y la transformación de los conflictos implica un compromiso con el conflicto individual, y un envolvimiento gradual con niveles más amplios de la vida social de esta manera, se podrán cambiar realidades inmediatas.

La educación para la paz tiene objetivos claros, que tienden a desarrollar habilidades de compromiso con la paz. Inician en un nivel personal-sin olvidar el social-, pues los individuos son el centro del fenómeno de la "responsabilidad". Los investigadores Reardon y Nordland lo plantean de la siguiente manera:

Todo individuo responsable tiene que mirar no solamente los problemas globales, sino también los específicamente locales, con lo cual podemos sacar otra conclusión: cada individuo responsable debe tener en mente no solo la humanidad, sino también los individuos, y poner atención, primero que todo, a la persona (Reardon and Nordland, 1994: 153)

Un sujeto comprometido y con sentido de responsabilidad, actúa de acuerdo

1. Traducción realizada por la autora 
con sus propias convicciones, pero simultáneamente toma en cuenta las de los demás, pues trata de ajustar su conducta, a valores humanos universales. La estructura de la responsabilidad social, desde el punto de vista del psicólogo ruso Lev Vigotsky (1978), es la unidad de tres componentes: cognitivo, motivacional y comportamental. El componente cognitivo, incluye el sistema de conocimientos de una persona acerca del compromiso social, incluyendo la esencia, los estándares y normas del comportamiento responsable. La base del componente cognitivo es una visión científica del mundo. Por su parte el componente motivacional, es el sistema de motivos e intereses que llevan a tener comportamientos socialmente responsables; dichos motivos, son los que orientan la realización de una actividad socialmente útil. Por último el componente comportamental, se plasma en la elección y suministro de líneas definidas de comportamiento, que correspondan con los estándares de la persona socialmente responsable (Reardon and Nordland, 1994: 172)

En esta misma línea de investigación, se encuentran teorías más recientes como la de Irene Comins Mingol, profesora de la Universidad Jaume I, quien propone una ética del cuidado que trasciende del nivel personal al nivel social. Así lo expresa:

Es fundamental crear espacios para las nuevas prácticas de una ciudadanía cuidadora y responsable: prácticas en donde las personas pueden manifestarse a sí mismas, como cuidadoras y/o receptoras del cuidado, en diálogo unas con otras, preocupadas por el bienestar propio, el de los otros y otras, y el de la naturaleza. De ese modo aparecen nuevas formas de acción democrática que integran el cuidado como eje vectorial, convirtiéndose así el cuidado en una práctica de política democrática participativa (Comins Mingol, 2008a: 26).

En suma, un nuevo nivel de conciencia, incluye la capacidad para crear una visión del mundo y comprender la participación de cada uno en la transformación de la realidad. Lo anterior implica un pensamiento crítico capaz de concebir múltiples enfoques, que permitan alcanzar la solución de problemas concretos, respetando el punto de vista de los otros. Estos planteamientos apuntarían a una verdadera educación, guiada por un sentido humano que orienta la responsabilidad social, no a través de la autoridad coercitiva, sino a través del respeto y la confianza en las capacidades de cada individuo.

\subsection{El Estado y su deber con la realización de la paz}

Se puede visualizar el interés del tema de la paz en la educación al analizarse uno de los objetivos que se contempla en Plan Decenal de Desarrollo Educativo 1996-2005, el cual «aspira articular todas las ideas y acciones que le den sentido a la gran revolución que implica la participación ciudadana en los asuntos esenciales de su destino y el ejercicio de sus derechos fundamentales» (Lerma Carreño, 2007: 19), uno de los objetivos que se vislumbra es de lograr que la educación sirva para el establecimiento de la democracia, el fomento de la participación ciudadana y la construcción de la convivencia pacífica (Lerma Carreño, 2007:19).

No obstante estos principios sólo están contemplados teóricamente, y se quedan a un nivel normativo con lo cual no se está garantizando la interiorizacion de dichos valores en los comportamientos de los educandos y sociedad en general, lo cual podría estar revelando una falencia en la implementación de políticas públicas que avalen la realización de tales derechos, ya que no es suficiente para un país la mera formulación de derechos fundamentales, esta tesis ha sido ampliamente investigada por profesor de la Universidad Nacional de Colombia, André Noel Roth, 2006, 2009.

Se considera de vital importancia realizar un análisis del derecho a Educación para la Paz en Colombia, a la luz de unas políticas públicas que puedan contribuir en garantizar su cumplimiento en todos los escenarios de vida del ciudadano y esta forma ayudar con la realización de una paz sostenible y duradera en Colombia ya que dichas políticas, «constituyen las herramientas desarrolladas por el Estado para favorecer y garantizar el cumplimiento y respeto a los derechos humanos considerados como bienes públicos fundamentales constitutivos de una sociedad» ( Roth, 2006: 60).

Es evidente que existe frente a este tema, una carencia en el diseño de estrategias que favorezcan la realización de la paz que se encuentra concebida como una obligación en constitución de Colombia, es muy claro que para su cumplimiento es necesario tanto el compromiso individual de cada ciudadano, como el institucional donde se incluye las organizaciones de formación primaria, secundaria, universitaria al igual que la familia. (Sánchez-Cardona, 2009b: 155-177). Esta tesis recobra su importancia, ya que existen grandes vacios en la pedagogía jurídica que facilite la implementación de estos lineamientos jurídicos en materia de educación y paz y de esta forma garantice 
el cumplimiento de la norma.

La sociedad no se cambia mediante la mera expedición de los derechos por decretos ni mediante la simple formulación de políticas. Las políticas públicas son un instrumento que necesita de credibilidad sociopolítica e implica por parte de los agentes públicos mucha dedicación así como el apoyo, vigilancia y participación de los ciudadanos y de organizaciones sociales y políticas fuertes y autónomas (Roth, 2006:192)

Con esta perspectiva se quiere hacer énfasis en la responsabilidad que tiene el Estado en primera instancia para regular y ejercer la suprema inspección y vigilancia de la calidad de la educación, de una manera especial le concierne velar por la formación moral de los alumnos (Lerma Carreño, 2007: 15). Sin embargo la constitución de Colombia de 1991, también hace explicito que la familia y la sociedad en general deben igualmente responsabilizarse por educar en el valor de la democracia y la paz. Sin embargo no se ha logrado comprometer a un buen número de personas en la realización de este deber constitucional, puesto que existe una gran debilidad en la promoción y divulgación del derecho a la educación para la paz parte de las estructuras institucionales. Podría pensarse que este mismo fenómeno sucede en general con todos derechos humanos en Colombia (Sánchez-Cardona, 2010: 141-160).

Las ramas del poder público que administran los derechos de la población no han incorporado a sus actividades el sentido de que su gestión la realizan para satisfacer los derechos de las personas o para asegurar su calidad de vida o para mejorar los sistemas de comunicación o para convocar a la población a desarrollar un compromiso conjunto en los derechos humanos (Maldonado Guerrero, 2007: 78)

Así mismo, se quiere expresar un acuerdo con la tesis de Maldonado Guerrero en cuanto a que en la perspectiva del Plan de desarrollo los derechos humanos no se vislumbra los derechos humanos como «una guía para la actuación entre el gobierno nacional y sociedad, lo que refleja una omisión de los derechos humanos como una cultura de vida y de relaciones cotidianas" (Maldonado Guerrero, 2007: 78). Fenómeno que pasa igualmente con el Derecho a la Educación para la Paz, de ahí la importancia de fortalecer y empoderar en toda la sociedad tanto la promoción del derecho a la paz como la realización de la misma.

\subsection{Las instituciones escolares y su compromiso con la paz}

4.3.1 El sistema educativo: eje central de la formación para la paz.

En las últimas décadas del siglo XX, la revisión y el replanteamiento de las metas de la educación ha sido el principal tema de la reflexión pedagógica, lo cual responde a dos motivaciones: la primera es la intención de que todas las personas logren construir un mundo mejor, más justo y solidario y la segunda, es la de observar y evaluar la realidad en que se vive (González Lucini, 2003: 13). En esta dirección se intenta que la educación sea la mejor arma para la paz, la cual debe ampliar y mejorar su horizonte de acción y sus metodologías, con el fin de restarle protagonismo a la guerra (Montessori, 2003: 55-56). De igual manera se pretende desarrollar contenidos de una formación integral, donde la educación sea vista como un proceso humanizador y democrático "como crecimiento interior del individuo", fundado en la constitución de ciudadanos para la paz, la convivencia y los derechos humanos (González Lucini, 2003: 16). Como lo diría Gimeno Sacristán, una educación para la vida que consiste en educar para un mundo en el que nada nos es ajeno (Gimeno Sacristán, 2005: 15).

Posiblemente la educación por sí sola, no acabará con las guerras ni con las profundas causas de otro tipo de conflictos violentos en el mundo; sin embargo, se trata de un camino al alcance de todos, que, con una adecuada orientación, nos permitiría conseguir la paz (Burguet Arfelis, 1999: 14-15). Los niños y las niñas son una esperanza clara, en la reorientación de la raza humana, hacia principios de convivencia y respeto por la vida (Montessori, 2003: 33). Desiderio de Paz Abril, pedagogo e investigador del tema de la paz en la escuela, plantea reconstruir la cultura organizativa de la educación, con el fin de que «permita a los jóvenes ciudadanos comprender e interpretar la realidad, y realizar una lectura crítica del mundo, que haga posible una educación hacia el compromiso y la acción y a favor de la justicia social y la equidad» (Paz Abril, 2007: 16-17).

Sin embargo, estos nuevos lineamientos educativos traen consigo una tensión entre metodologías viejas de enseñanza (las cuales no aceptaban un pensamiento crítico por parte de los estudiantes) con las propuestas nuevas en la educación, que ahora se incrementa debido a que nuevas dimensiones tales como la enseñanza para la paz, además de promover el pensamiento crítico, tratan también los aspectos alusivos a la enseñanza y el desarrollo de actitudes, esperanzas, temores, creencias, frustraciones y sueños. Este sistema educativo 
para la paz, se basa en la exploración de condiciones y valores entre los jóvenes, como un medio que posibilita la expresión de sus ideas, sin miedo ante la crítica negativa de la generación precedente (Hicks, 1988: 29). En este sentido, estas nuevas metodologías basadas en la educación para la paz, cambian la forma de ver a los educandos, ya que ahora se les percibe como sujetos activos que tienen los mismos derechos de expresión que los educadores, y se encuentran a un mismo nivel de comunicación. En esta misma línea de investigación, aparecen los aportes de investigadores en paz y educación tales como David Hicks, (1988: $232)$, Xesus Jares $(2003,90)$ y Paulo Fraire $(2005: 80)$, quienes plantean que los educadores actuales, deben poseer adecuadas relaciones interpersonales con los educandos, basadas en el afecto y el respeto, ya que la dirección de autoridad no debe ser vertical sino horizontal.

Del mismo modo, un enfoque positivo de la Educación para la Paz, es dar a conocer que los seres humanos no son por naturaleza violentos, y que las raíces de la violencia están relacionadas más bien con variables psicológicas y sociales que con nexos genéticos. Como sustento de este enfoque, aparece el desarrollo de teorías humanistas en la educación, las cuales tienen la confianza de que el individuo puede cambiar las generaciones futuras y no está condenado a perpetuar la violencia por razones biológicas; esta tesis deja una gran ventana abierta en la formación de sujetos en pro de la cultura de la paz, espacio que se aprovecha en el área de las ciencias socio-pedagógicas.

Afortunadamente, existen muchos docentes que quieren hacer reflexiones acerca de su quehacer humano en las aulas, con el fin de mejorar los procesos de aprendizaje con sus estudiantes. Cuando dichas personas logran realizar proyectos de autoformación en temas socio-afectivos en sus instituciones, aumenta en ellos el interés por propiciar espacios para que los educadores expresen sus emociones de afecto a los estudiantes. Esta tesis se demostró en una investigación realizada en el colegio Hunza localidad de Suba en Bogotá (2008-2010) y se ve reflejada en las siguientes gráficas.
LENGUAJE AFEctuoso

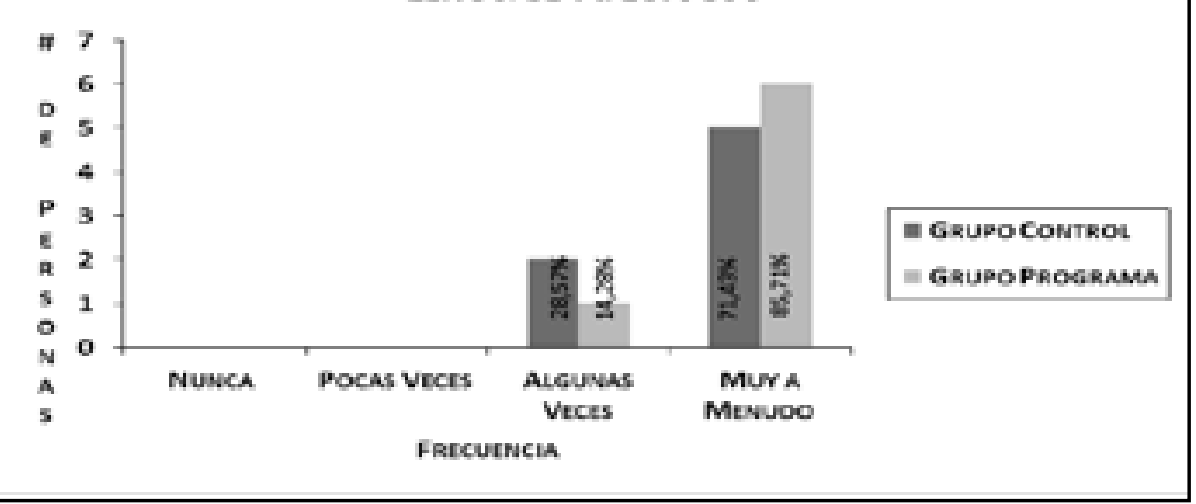

Gráfica 1. Utiliza un lenguaje afectuoso con los estudiantes

En la Gráfica anterior, se puede observar que un $85,71 \%$ de los docentes que participaron en el proyecto de formación en temas de paz, muy a menudo utilizan un lenguaje afectuoso con los estudiantes. Mientras que el $71,43 \%$ de quienes no han tenido esta formación (grupo control), contestaron que muy a menudo expresaban un lenguaje afectuoso. Sin embargo es posible imaginar que el porcentaje alto obtenido en el grupo control, puede ser menor ya que la imagen de deber ser del docente influye en la honestidad de las respuestas. Adicionalmente esta variable es más evidente cuando las personas no han realizado procesos de sensibilización en dichos temas, ya que ha no habido un desarrollado igual de niveles de conciencia frente a como se dan los procesos de comunicación afectiva en sus aulas.

Actualmente, se sigue investigando el tema de la paz unido al de la educación, como una de las mejores opciones para crear una verdadera cultura de la paz, basada en el reconocimiento del otro. La metodología de ese sistema de reconocimiento se desarrolla, enfatizando más en los comportamientos que se han dada adecuadamente a través de retroalimentaciones positivas que ayuden en un futuro a las personas a encontrar sus virtudes interiores a pesar de los errores cometidos, José Tuvilla ha planteado que el reconocimiento de los otros incide de manera positiva en una cultura de paz reflejada en las relaciones diarias entre los compañeros de la escuela (Tuvilla Rayo, 2004a: 271). Esta idea concuerda con la perspectiva de Jares (2001) cuando plantea que dicha cultura está basada en el respeto y el reconocimiento del otro, en 
el entendimiento y en la búsqueda de acuerdos con principios de igualdad, dignidad, justicia y equidad; así mismo se fundamenta en el diálogo; en el compromiso y la solidaridad; en la cooperación y en la ternura de los pueblos (Jares, 2001: 119-123).

Es importante recalcar que la enseñanza basada en la emocionalidad y el afecto es uno de los ejes primordiales de esta investigación y concuerda con los planteamientos de Alejandro Romero Hernández (2009), en cuanto a que la educación debe llegar a un equilibrio en el cual la formación intelectual vaya de la mano con la formación espiritual, emocional y humanista. Un intelecto sin corazón, puede generar desequilibrios sociales y económicos que afectan a toda la sociedad (Romero Hernández, 2009: 61-120). Vale la pena enfatizar que para ello, se requiere de una transformación en la función o identidad de los maestros que intervienen en la acción educativa, al igual que se hace necesario potenciar en los centros escolares, el trabajo en equipo con el fin de desplegar una cultura participativa basada en el diálogo y los compromisos colectivos. Lo anterior juega un papel importante ya que en muchos centros educativos, los docentes tienen la dificultad de encontrar los espacios, medios didácticos y apoyo en general por parte de la institución, para llevar a cabo los proyectos pedagógicos, tendientes al logro de una educación para la paz, basada en derechos y democracia (González Lucini, 2003 20).

En suma la consecución de una paz sostenible en el planeta, requiere de nuevos paradigmas y formas de pensarla; de una manera muy especial, exige cambios en la forma de ver la educación, donde se incluya el entendimiento de un ser humano en formación, que está dotado de un gran potencial para cambiar todos los días su comportamiento en el mundo. Este proyecto de formación del individuo en cada momento de su vida, podría aprovecharse desde la educación para reorientar y fortalecer el camino de la paz.

4.3.2 Edificación de la paz basada en la formación de virtudes Existe un consenso general en que la educación, es la que debe dirigir el tránsito hacia la cultura de paz; esto implica una ruptura con metodologías en la pedagogía de la enseñanza, basadas en principios eminentemente teóricos e instrumentales del proceso de aprendizaje, ya que aquellos afectan la posibilidad de una educación orientada hacia la convivencia pacífica.

La construcción de la paz es una obra permanente, multidimensional y dinámica que requiere el enraizamiento de valores pacíficos en la población. Debido a que la paz se construye, se aprende, nadie nace con los valores y actitudes que la avivan. Aquí radica la importancia de una educación para una auténtica cultura de paz, ella es a la vez una estrategia y un componente privilegiado para lograrlo (Manjarres y Molano, 2001: 34, 35)

Teniendo en cuenta dichos planteamientos, se ha propuesto avanzar en una práctica educativa que tenga en cuenta los talentos del desarrollo humano, por ejemplo enseñar a pensar, construir una educación socio-emocional y una basada en valores que promuevan una ética fundamentada en la justicia, la creatividad y la imaginación (Paz Abril, 2007: 30). Es así que una formación cimentada en virtudes como lo plantea Linda Kavelin Popov (2000) en su libro El Proyecto de Virtudes, busca hacer énfasis en las mejores cualidades latentes en los niños, estimulándolos a dar lo mejor de sí, es su libro la autora hace una diferenciación del concepto de valor y virtud «mientras que los valores son específicos a una cultura, las virtudes son apreciadas universalmente para todas las culturas» (Popov, 2000: xix), por consiguiente propone educar más con base en las virtudes, ya que lo que en una cultura se aprecia como positivo, en otra cultura puede ser visto de otra forma. La misma autora plantea crear una cultura que fortalece el carácter de cada individuo, en una atmósfera de amistad, confianza, afecto, amabilidad en las cuales estas virtudes son igualmente apreciadas tanto como el éxito académico (Kavelin Popov, 2000: 58)'.

Sin embargo, en la extensa bibliografía sobre el tema, se ha utilizado con mayor frecuencia el término de valor en la educación, por ejemplo el investigador John Burton lo ha definido como una idea, hábito, costumbre o creencia que caracteriza a los individuos o ciertas comunidades en particular (Burton, 1990: 37). Para algunos autores, la diferencia entre virtud y valor no resulta importante en las discusiones teóricas, aunque la presente investigación, reconoce que la formación en virtudes, realmente puede ofrecer una perspectiva más proactiva sobre las bondades del ser humano que la perspectiva de los valores.

Una de las discusiones más visibles en relación con la educación en valores o virtudes, tiene que ver con la falencia de modelos que integren las dos concepciones, ya que la educación centrada en valores pareciera no ser suficiente para garantizar el cambio de actitudes en los individuos, y fortalecer el compromiso con la paz. Autores como Berkowitz, profesor de la Universidad de Marquette en Estados Unidos (1998) y, Puig Rovira (1998), profesor de la Universidad de Barcelona, han planteado una educación moral, con la idea de buscar la integración de los modelos «no obstante, nos faltan

1 También se puede revisar el libro de guía de virtudes para la familia, de Kavelin Popovy y otros (2002) donde se enseña a los padres de una manera didáctica como aplicar las virtudes en la convivencia familiar. 
argumentos de plena integración, de síntesis o de unidad. En cambio, tenemos una situación en la que cada perspectiva proclama ser la correcta e intenta encarecidamente desacreditar a las demás» (Berkowitz, 1998: 141).

En conclusión, plantear una educación basada en virtudes o el carácter, implica la inclusión de valores y por lo tanto podría considerarse como un modelo positivo, integrador y holístico, puesto que, «necesitamos volver a creer en el ser humano como tal y en sus capacidades de actuar de una manera altruista, generosa, solidaria» (Oller, 2002:6). Se considera importante dar una mirada general a este enfoque, con el ánimo de buscar dicha integridad y unidad en una serie de argumentos que tiende en última instancia a ver la paz como aquella motivación que debe impulsar las interacciones cotidianas de las personas, Samay la denominaría emoción moral (Samay, 1986: $71-$ 72). Para el filósofo Juan Antonio Marina, toda educación ética debe empezar por una educación afectiva, que tienda hacia la vivencia de los valores y no sólo a su transmisión nominativa, pues sólo los que logran integrarse en las experiencias de vida son los que poseen la verdadera fuerza motivacional en los comportamientos (Marina, 2003: 27, 28).

La educación para la paz en aras de apuntar a la convivencia armónica, requiere del fortalecimiento de valores, actitudes y comportamientos que vayan de la mano con el desarrollo de la autoestima, y el respeto de sí mismos, componentes indispensables en el ejercicio de la cooperación, la solidaridad y la tolerancia (Jiménez Bautista, 2008: 179-183; Tuvilla Rayo, 2004a: 138, 220-221, 225-226). Hasta aquí queda claro que parece que existe un consenso entre muchos investigadores, en que el aprendizaje de valores o más propiamente de virtudes es trascendental para desarrollar una verdadera cultura de la Paz, ahora bien se necesita pensar cuando es mejor empezar con este proceso de formación y que instituciones educativas deberían liderar esta enseñanza en la sociedad actual.

Cabe destacar que las actitudes pacíficas requieren de un ambiente de aprendizaje que sea eficaz para garantizar la práctica cotidiana de dichos valores y virtudes. Según las teorías del aprendizaje, entre más temprano en el desarrollo humano se inicie dicha formación, se conseguirán mejores procesos de paz en la sociedad por consiguiente, el papel de los padres, la escuela y las demás instituciones sociales, es muy importante en este proceso de formación, adicionalmente Cava y Musitu (2002) anota que los valores no deben ser impuestos, sino buscar los medios para que sean introyectados en cada persona como forma de garantizar que estos se conviertan en parte de cada experiencia de vida (Cava y Musitu, 2002: 22-23).
En el siguiente apartado de este capítulo, se explicará la responsabilidad con la paz de instituciones educativas como la familia y la universidad. Es de suma importancia enfatizar que los primeros procesos de formación en paz, se inician desde el hogar, donde los padres cumplen un papel importante, al servir de modelos de vida inicial para los niños, hecho que debería extenderse a los colegios a través de la formación en virtudes-tema que se ha venido desarrollando a lo largo del capítulo. Sin embargo este aprendizaje debe prolongarse también hacia las instituciones universitarias, ya que estas juegan un importante papel al conectar el aprendizaje, con los roles que desempeñará cada individuo en los sistemas sociales, económicos y políticos de cada comunidad humana. Dichas instituciones, deberían contribuir en última instancia con la formación de ciudadanos con un alto compromiso social.

4.4 La familia como institución de paz

Uno de los principales retos de los padres de familia y los centros educativos, es promocionar o desarrollar estrategias formativas que contribuyan a la construcción de relaciones pacificas en la sociedad en general. La responsabilidad de la convivencia armónica, entendida como el vivir juntos en determinadas relaciones sociales y códigos valorativos en un determinado contexto social (Jares, 2006: 17), no puede dejarse sólo en manos de las entidades estatales y/o instituciones escolares, pues el futuro de los hijos es en gran parte competencia de los padres de familia.

Los planteamientos con respecto a quien tiene la mayor responsabilidad en la adecuada educación de los niños, es uno de los problemas que se vive a diario en Colombia, tanto en los escenarios educativos como familiares. Se escucha con gran frecuencia en los colegios, que los orígenes de la violencia en los estudiantes están asociados a las interacciones negativas en las familias y, cuando se analiza el mismo problema en los hogares, los culpables resultan siendo los colegios. Este proceso de lanzarse la pelota unos a otros, causa la mayor tensión a la hora de solucionar problemas de convivencia con los estudiantes, lo cual no contribuye positivamente en la transformación de los conflictos.

En cuanto a dicho fenómeno, el catedrático de la Universidad de Coruña, Xesus Jares ha planteado similares dificultades en las relaciones de familia-escuela, en países como España, donde a veces se tornan distantes y difíciles, lo que dificulta el trabajo en equipo en la formación de los niños en temas de paz y convivencia. El autor ha encontrado, en un estudio realizado en Galicia sobre el tema de conflicto y convivencia en los centros educativos de secundaria entre los años 1998 y 2002, que no se percibe una responsabilidad equitativamente compartida entre la familia y los educadores en relación con la formación de los niños en estas temáticas. Se percibe una tendencia a 
recargar mayor trabajo en una u otra parte. Se ha observado un claro inconformismo de un sector de docentes en relación con el poco compromiso de los padres y las madres de familia, en la educación de sus hijos. Sin embargo, vale la pena aclara que en algunos casos, el inconformismo también procede de los padres y las madres, quienes no se sienten convocados por la comunidad educativa para enfrentar estas temáticas, y presencian en ciertas ocasiones, la resistencia del cuerpo docente ante tales iniciativas. De una manera muy concreta, el estudio plantea que existe un gran vacío en la convivencia democrática dentro de los colegios, lo cual exige la creación de espacios de diálogo y la construcción de estrategias para mejorar esta carencia de formación en la familia y las escuelas (Jares, 2006:143-148).

En esta misma dirección, es importante anotar que el anterior fenómeno, se ha comprobado en el proyecto realizado en la ciudad de Bogotá con un grupo de profesoras y profesores que se formaron en modelos de paz durante los años 20082010. Se encontró una queja reiterativa de parte de los educadores: se sienten abandonados en este trabajo y piensan que en muchas ocasiones, los padres dejan los hijos en la escuelas esperando que las carencias de afecto y los problemas de comportamiento sean resueltos por los profesores, lo cual genera en ellos un sentimiento de aislamiento en el desempeño de sus roles. Del mismo modo, hacen falta en las instituciones, espacios adecuados para desarrollar programas de formación en temas de paz. Pareciera -como dice Xesus Jares (2006)- que no existe reciprocidad entre las responsabilidades adjudicadas por el cuerpo docente a los padres y madres, ni tampoco existen suficientes espacios ni actividades, que la institución cree para tal fin (Jares, 2006: 145). El mencionado autor señala que los maestros y las maestras encuentran en las familias, el epicentro de la violencia y la conflictividad que se da en los centros educativos (Jares, 2006: 145). Dicha tesis es sostenida igualmente por otros autores como María José Díaz (2002) y Alejandro Romero Hernández (2009), quienes sostienen que la gran parte de la violencia que existe actualmente, tiene su origen en la violencia familiar (Díaz, 2002: 62).

La anterior reflexión es relevante para aclarar algunas intervenciones en el área de familia, que han ocurrido en Colombia, donde es explícito que la creación de formas pacíficas de vida, debe comenzar en el seno familiar. En muchas ocasiones el manejo de los conflictos al interior de las familias, degenera en nuevas situaciones de agresividad, debido a la no aceptación de las diferencias de sus integrantes.

Cuando los miembros de la familia aceptan ir a las asesorías psicosociales, logran aprender habilidades de comunicación basadas en el afecto, que mejoran significativamente la convivencia en los hogares. En esta misma dirección, se aprende a focalizar más en los logros y aspectos positivos de la relación, que en castigar los fracasos o conductas negativas. Dichas metodologías psicológicas, buscan promover la ejecución de mejores comportamientos pro-sociales en la familia. De otro modo, se ha comprobado que una vez que los involucrados en este proceso practiquen estos principios, podrán romper el círculo vicioso de la violencia en la familia y contribuir con una sociedad más pacífica, a partir del reforzamiento de los gestos de amistad o símbolos de paz que previamente se habían ignorado. Estos resultados están basados en la tesis de que las personas que nunca aprendieron a felicitar y a reforzar en los demás sus facetas positivas, sino que siempre reprocharon, castigaron lo malo y tuvieron relaciones basadas en la crítica, suelen ser una fuente de malestar, de dolores, tensiones y conflictos constantes (Lopera, 2006: 91).

En Colombia se estuvo trabajando con grupos de madres aplicando esta misma metodología, con algunas dificultades iniciales para desarrollarla, debido a que desean que sus niños cambien comportamientos violentos en poco tiempo. Del mismo modo, algunas madres acusaban a los niños, como los únicos responsables de su mal comportamiento, por ejemplo: "él es muy tremendo y él es el que tiene que cambiar, porque nosotros no hacemos nada malo". Se percibió un escaso reconocimiento de la responsabilidad que les asiste en el origen del problema, por consiguiente, se pudo comprobar la existencia de una pobre consciencia acerca de la necesidad de iniciar un cambio significativo en la forma de ver el problema e intervenir en él, con el fin de mejorar las relaciones en la familia. En estos programas de formación, se logra constatar que si los padres comienzan a cambiar de actitud frente a los hijos, éstos a su turno cambiarán su comportamiento más fácilmente manteniéndolo por más largo tiempo en sus vidas, debido a que sus padres se convierten en modelos de paz en el hogar y promotores de procesos de paz.

A pesar de los obstáculos que se presentan a los padres, con el fin de llevar a cabo una adecuada educación de sus hijos, también se debe admitir que algunas veces los padres de familia suelen culparse injustamente por la violencia que sus niños ejercen en casa y llevan al aula de clases, porque en ocasiones los mismos padres, son también víctimas de la violencia así como sus hijos. Muchos de ellos, a pesar de hacer sus mejores esfuerzos para cambiar, son incapaces de proteger plenamente a sus niños contra la violencia que permea la sociedad. Por lo tanto se hace necesario la intervención profesional en diversas familias para ayudar a los cambios en la interacción con los hijos. Según Diane Levin (2003) entre más lazos podamos crear entre el hogar y la escuela, mayor será nuestro impacto en la promoción de la convivencia pacífica entre los niños y sus familias (Levin, 2003: 7). Esta tesis es igualmente apoyada por Cava y Musitu (2002) quienes afirman que la familia influye en la escuela y viceversa y, en 
consecuencia, es fundamental que tengan una comunicación abierta y una actitud de colaboración mutua. Si ambos contextos plantean su relación desde estos parámetros y concentran su atención en aprovechar sus posibilidades y potencialidades, mejoraría el desarrollo integrar de los alumnos (Cava y Musitu, 2002: 45). Cabe destacar que en esta investigación, se coincide con Jares (2006), cuando plantea que es necesario unir a las familias y el cuerpo docente, con el fin de conformar lazos de hermandad y trabajo (Jares, 2006: 150-151).

Ahora bien, fomentar la cultura de la paz como se ha venido exponiendo a lo largo de esta investigación, es un cometido de varias instituciones como la familia y la escuela, pero también amerita la intervención de las universidades tanto públicas como privadas, de manera tal que se pueda dar continuidad al compromiso social con la paz. Por consiguiente en el último apartado de este capítulo, se analizará el papel que juegan estas instituciones en la consecución de una paz duradera.

4.5 La institución universitaria como constructora de paz.

En países como Colombia, existe una gran falencia en cuanto a la articulación de los temas de paz en el pensum académico de las universidades. Se quiere introducir tangencialmente en este apartado que la formación en la paz, no culmina cuando los jóvenes dejan los colegios. Las instituciones universitarias, tienen la misión de preparar a los futuros profesionales de una forma integral, puesto que ellos serán quienes liderarán los grandes cambios a favor de la paz, al interior de cada organización donde laboren. Edgar Morín (2007) plantea que la universidad debe a la vez adaptarse a las necesidades de la sociedad contemporánea y efectuar su misión transecular, orientada al apoyo de los ciudadanos en la vivencia plena de sus destinos; del mismo modo, debe fortalecer la conciencia autónoma de sus estudiantes haciendo primar la verdad sobre la utilidad y permitiendo de ese modo, el enriquecimiento del patrimonio cultural sin el cual no seriamos más que máquinas de producción y consumo (Morín, 2007: 110).

Como bien lo esboza Xesus Jares (2003), la educación para la convivencia no pretende enseñar únicamente determinadas estrategias, pretende construir una nueva cultura y relaciones sociales donde la violencia no tenga cabida y se propicie una cultura de paz que proclame el respeto a la diferencia, la diversidad del florecimiento individual y colectivo como patrimonio de la humanidad (Jares, 2003: 99). A partir de los escenarios universitarios se necesita promover grandes proyectos sociales que tengan eco y viabilidad en la promoción de la cultura de la paz, en diferentes contextos, por ejemplo: las escuelas, las familias, las organizaciones no gubernamentales entre otros y, donde se contemple la definición de la paz de manera integrada. Lamentablemente la educación en derechos humanos que velaría por la libertad, la justicia y la digna convivencia de los seres humanos, no se ve presente en los currículos de las universidades, como una parte de la formación de los estudiantes (Jares, 2006: 20,104).

La educación para la paz en las universidades, requiere de espacios donde se reconozcan los problemas tanto a nivel local como nacional y global con el ánimo de involucrar a los estudiantes en la búsqueda de estrategias que permitan transformar dichas realidades. En este aspecto, es necesario dirigir discusiones alrededor de estos temas, teniendo en cuenta que el aprendizaje en este nivel educativo, es de personas adultas y, por consiguiente, el compromiso debería ser mayor. Este planteamiento se profundiza con la tesis de Jiménez Bautista (2004), quien sugiere que la paz, entendida como una realidad social, (económica, política y cultural) debe ser investigada por todas las personas, ya que los seres humanos somos actores de paz y portadores de su «virus». Por lo tanto, poseemos un gran potencial para la consecución de un mundo más justo y perdurable (Jiménez Bautista, 2004: 22). Ahora bien, si se parte de este supuesto, el reto de la universidad sería la creación de metodologías pedagógicas que ayuden a hacer realidad esta tesis en cada uno de los proyectos de los que forman parte los estudiantes universitarios.

Los rasgos de ese aprendizaje social por parte del alumnado en las universidades con frecuencia son los siguientes: se aprende la fragmentación mental en un currículum centrado en disciplinas aisladas; la competitividad; se aprende una doble moral pues importan más los títulos o el examen aprobado, que el saber en sí mismo, lo que supone una desnaturalización del aprendizaje, se aprende la sumisión, la obediencia, la pasividad intelectual, el miedo a implicarse en conflictos en la comunidad educativa, ante posibles pérdidas en lo personal o ante el convencimiento de que las cosas seguirán igual; la reproducción de la cultura en letra impresa y la dependencia de la información del profesor (Fernández Herrería, 2000: 119).

Frente a la dificultad planteada por Fernández, en cuanto al aislamiento de las disciplinas en los currículums, Morín (2007), propone que las universidades por ser centros de investigación de los problemas de la complejidad y la transdisciplinariedad deberían liderar talleres dedicados a analizar dichos problemas al interior de las aulas (Morín, 2007: 114). Igualmente en la teoría de Freire se aprecia algunas salidas, a los problemas expuestos por Fernández, el cual propone que en una educación para la libertad, el educador no es aquel que sabe y trasmite, es quien problematiza e investiga, y el educando no es un recipiente para ser llenado, sino un sujeto crítico que cuestiona y construye conocimientos a través del diálogo y la reflexión (Freire, 2005: 93).

Existen algunas experiencias en universidades en Bogotá, tanto a nivel público como 
privado, donde se han propiciado espacios para investigar la paz, arrojando muy buenos resultados. Por ejemplo en la Universidad Distrital, de carácter público, en el último semestre de la carrera en la materia de Gestión Educativa y dentro del área de pedagogía infantil, se propician prácticas donde los estudiantes se involucran en diferentes proyectos con colegios y ONG's, con el ánimo de vivenciar aquellos escenarios y a partir de esta experiencia investigar y aportar en la creación de metodologías sociales de cambio de realidades inmediatas, a las que luego se integrarán -en el corto o mediano plazo- a nivel profesional. En dichas prácticas se ha tenido la oportunidad de gestionar proyectos en temas de afrocolombianidad, derechos humanos, convivencia y paz, medio ambiente y sexualidad. De estas prácticas universitarias se puede concluir primero, que los estudiantes tienen un gran interés de involucrarse en temas de paz; segundo, que quieren cambiar realidades sociales porque las consideran como un gran reto profesional y, tercero, que existe una alta motivación para liderar estos proyectos y aportar con sus conocimientos en las diferentes instituciones.

De la misma manera, en el Departamento de Psicología con énfasis social de la Universidad Luís Amigo, de carácter privado, se propuso un semillero de Política y Paz, cuyo objetivo era investigar este tema a partir de la motivación de prácticas afines y la discusión y análisis de diversos temas desde la psicología y, finalmente, encauzar el desarrollo de las posibles tesis de grado alrededor del tema de Paz y Política.

Queda claro a partir de dicha tesis, que el papel de la universidad como institución de formación en procesos humanos es trascendental, especialmente en un país con intención democrática como Colombia. Entonces la labor de la educación según Maturana (2002) es crear, realizar y validar la convivencia, a través de una red de conversaciones que entrelacen el hacer y el emocionar, formando así ciudadanos autónomos, sociales y ecológicamente responsables (Maturana, 2002: 147). Es importante aquí recordar el pensamiento de Freire (2005), cuando plantea que la verdadera educación es un proceso humanizador, dinámico y permanente, que no acepta un presente bien comportado ni tampoco un futuro preestablecido, lo que la hace revolucionaria y esperanzadora (Freire, 2005: 97-98).

En suma, se ha querido reflexionar aquí que muchas veces las instituciones educativas, no brindan a sus estudiantes las opciones necesarias para pensar en los temas concernientes a la educación para la paz y, lamentablemente, se pierden grandes oportunidades de avanzar en la cultura de la paz, o se suele castigar las buenas iniciativas que pudieran desarrollarse en pro de la cultura de paz desde las universidades. Se requiere entonces cada vez más, abrir espacios en torno a la paz desde la academia, con el ánimo de escuchar y hacer visible un sin número de voces de estudiantes universitarios, que quieren contribuir en la construcción de un mundo mejor.

\section{Conclusiones}

El fenómeno de la cultura es un constructo mental y afectivo que se desarrolla y se aprende a lo largo de la vida del ser humano, a través de las experiencias y vivencias cotidianas que se tienen con el mundo; por consiguiente dicho fenómenos es dinámico, flexible y siempre susceptible al cambio. Las elaboraciones teóricas que los individuos haga acerca de la Paz, son de vital importancia, ya que servirán como guías de comportamiento y de ellas dependerá hasta donde se quiere llegar con el compromiso de la paz.

Los objetivos plasmados en la educación para la paz, indudablemente apuntan a empoderar la cultura de paz en el planeta, sin embargo ello se podrá alcanzar con el esfuerzo mancomunado de la sociedad, donde el aporte personal e institucional será trascendental en este cometido. En esta dirección en el caso especifico de Colombia el El estado deberá vigilar por el cumplimiento de la normatividad en cuanto al tema de la obligatoriedad de la educación para la paz en las instituciones educativas, al igual al interior de los colegios se debe desarrollar de manera transversal una formación en el tema de la paz, la cual debe ser coherente con la educación impartida en las familias. Por último se considera que las universidades a su vez tienen un compromiso en formar a los nuevos ciudadanos en actores sociales, capaces de gestar procesos de cambios, que garanticen una paz viable y duradera en la sociedad.

\section{Bibliografía}

- BERKOWITZ MARVIN (1998): «Educar la personalidad moral en su totalidad» en Educación Valores y Democracia. Madrid, Organización de Estados Iberoamericanos para la Educación la Ciencia y la Cultura (OEI), 139-177

- BOBBIO, NORBERTO (1966): El problema de la guerra y las vías de la paz, Barcelona, Gedisa.

- BURGUET, ARFELIS, MARTA (1999): El educador como gestor de conflictos, Bilbao, Desclée De Brouwer.

- BURTON, JOHN (1990): Conflict, Resolution and Prevention, London, The Macmillan Press Ltda

- CAVA, MARÍA JESÚS Y GONZALO MUSITU (2002): La convivencia en la escuela, Barcelona, Paidós SAICF, 189-190.

- COMINS-MINGOL IRENE (2009): Filosofía del Cuidar una propuesta coeducativa para la Paz, Barcelona, Icaria Editorial, S.A. 
Editorial Icaria.

(2008a): La ética del cuidado y la Construcción de la Paz, Barcelona,

- CREWS, ROBIN (2002): «A Modest Proposal, Towards a Peace Studies that studies Peace, not its Absence», In: Peace Review, Vol. 14, Issue 1 March, 73-80.

- DANESH, HOSSAIN (1979): The violence frees Society. A Gift for our Children. Ottawa, Bahai Studies Publications

- DÍAZ-AGUADO, MARÍA JOSÉ (2002): «Violencia y Convivencia Escolar: Por una cultura de la convivencia democrática», Revista Interuniversitaria de formación del profesorado, No. 44, 55-78.

- FERNÁNDEZ-HERRERÍA, ALFONSO (2000): «La educación para la paz en la universidad», en RODRÍGUEZ ALCAZAR, JAVIER (ed.): Cultivar la paz: perspectivas desde la Universidad de Granada. Granada, Editorial Universidad de Granada, 113-124.

- FISAS, VICENC (2002): La paz es posible, Una agenda para la paz del siglo XIX, Barcelona, Plaza \& Janés Editores.

- FREIRE, PAULO (2005): Pedagogía del oprimido, México D.F, Siglo Veintiuno Editores.

- GILLIGAN, CAROL (1986): La moral y la teoría. Psicología del desarrollo femenino, México, Fondo de Cultura Económica.

- GIMENO SACRISTÁN, JOSÈ (2005): La Educación que aun es posible. Madrid, Morato

- GONZÁLEZ LUCINI, FERNANDO (2003): «La educación como tarea humanizadora de la teoría a la práctica», en Aprender a convivir en la escuela, Madrid, Universidad Internacional de Andalucía, Ediciones Akal SA, 13-25

- HARRIS, IAN M. (1988): Peace Education, Jefferson, N.C, McFarland.

- JALALI-RABBANI, MARTHA (2001): La educación para la Ciudadanía Mundial, Toluca, Ed. Universidad Autónoma del Estado de México.

(2009): "Ciudadanía, justicia social y la lucha por el reconocimiento», en Pensamiento Jurídico, No. 26, 92-112

- JARES, XESUS (1994): «Educación para la Paz y Organización Escolar» en ALFONSO FERNÁNDEZ (Ed.): Educando para la Paz: Nuevas propuestas, Granada, Universidad de Granada, 285-316.

- (2001): Educación y conflicto, Guía de educación para la convivencia, Madrid, Editorial Popular.

(2003): «Educación para la paz y el aprendizaje de la convivencia» en Aprender a convivir en la escuela, Madrid, Universidad Internacional de Andalucía, ediciones Akal SA, 87-105

(2006): Pedagogía de la Convivencia, Barcelona, Editorial Grao.

- JIMÉNEZ-,BAUTISTA, FRANCISCO (2008): «Cultura de paz, educación y valores» en
Universidad Autónoma del Estado de México: Comunicación, educación y cultura de paz, México D F, Ed, Porrúa, 165-185.

- (2004): "Propuesta de una Epistemología Antropológica para la Paz», en Convergencia, Revista de Ciencias Sociales, No. 34, 21-54.

- KAVELIN-POPOV, LINDA (2000): El proyecto de virtudes, Guía para los educadores, Torrance, Jalmar Press.

- MAYOR, FEDERICO (1996): UNESCO publishing Tolerance, Cultures of Peace, Paris. McGraw-Hill.

- MALDONADO GUERRERO, LUIS FERNANDO (2007): Los Derechos Humanos como política pública, Bogotá, Universidad Nacional.

- MANJARRÉS-PEÑA MARIA HELENA Y MILTON MOLANO-CAMARGO (2001): La escuela que los niños perciben: aportes para construir una cultura desde una gestión institucional. Bogotá, Ed. Universidad Pontificia Bolivariana.

- MARINA, JOSÉ ANTONIO (2003): «De los sentimientos a la ética», en Aprender a Convivir en la Escuela, Madrid, Universidad Internacional de Andalucía, Ediciones Akal SA, 27-39.

- MATURANA-ROMESIN, HUMBERTO (2002): Transformación en la convivencia, Santiago de Chile, Dolmen Ediciones S.A.

- MARTínEZ-GUZMÁN, VINCENT (2005): Podemos hacer las paces, Reflexiones éticas tras el 11-S y el 11-M, Bilbao, Ed. Desclée de Brouwer.

- MONTESSORI, MARIA (2003): Educación para la paz, Buenos Aires, Ed. Longseller.

- MORÍN, EDGAR (2007): La mente bien ordenada, Barcelona, Ed. Seix Barral.

- NODDINGS, NEL (2005): The change to Care in Schools, The Challenge to Care in Schools: An Alternative Approach to Education. Advances in Contemporary Educational Thought, Second edition, New York and London, Teachers College Press.

- LERMA CARREÑO, CARLOS ALBERTO (2007): El derecho a la educación en Colombia, Buenos Aires, Flape.

- LEVIN, DIANE E. (2003): Teaching young Children in violent Times, Building a Peaceable Classroom, Cambridge, MA: Educators for Social Responsibility

- LOPERA, JAIME (2006): El lado humano del conflicto, Bogotá, Intermedio. 73-91

- Oller SALA, MARIA DOLORES (2002): Un futur per a la democracia. Barcelona, Cristianisme I Justicia.

- PAZ-ABRIL, DESIDERIO (2007): Escuelas y Educación para la Ciudadanía, Global, Barcelona,

- Intermòn Oxfam Ediciones.

- PUIG ROVIRA, JOSEPH (1998): “Construcción Dialógica de la Personalidad Moral» en Educación Valores y Democracia, Madrid, Organización de Estados Iberoamericanos para la Educación la Ciencia y la Cultura (OEI), 179-202 
- REISS, HANS ED (1970): Kant's Political Writings, Cambridge, Cambridge University Press.

- REARdon, BeTtY AND eVA NORDLAND (1994): Learning Peace: The promise of ecological and cooperative education, Albany, State University of New York Press.

- ROJAS-CLAROS, ARMANDO (2008): «Reseña de Ética Mundial en Latino América de Hans Küng», en Ideas y Valores Revista Colombiana de Filosofía Universidad Nacional Colombia, No. 137, 149-151.

- ROMERO-HERNÁNDEZ, ALEJANDRO (2009): Hacia una pedagogía para la paz, Bogotá, Fotolito Herbol Ltda.

- ROTH, ANDRÉ NOEL (2006): Discurso sin Compromiso, Bogotá, Ediciones Aurora.

(2009): Políticas Públicas: Formulación, implementación y evaluación Bogotá, Ediciones Aurora

- SAMAY, SEBASTIAN. A. (1986): «Affectivity: The power base of moral behaviour», en G.F. MCLEAN, F.E. ELLROD, D. L. SCHINDLER Y J. A. MANN (ed), Act and agent: Philosophical foundations for moral education and character development, Nueva York, University Press of America, 71-114

- SÁNCHEZ CARDONA, MARIELA INÉS (2010) «La educación para la paz en Colombia: Una responsabilidad del Estado social de derecho», en Revista Vía Juris, No.9, Universidad Libertadores. 141-160.

- (2009) «El compromiso constitucional a la Educación para la Paz: ¿una promesa no cumplida?», en MARQUARDT, BERND (Ed.), Constitucionalismo Comparado, Acercamientos metodológicos, históricos y teóricos, Bogotá, Ed. Universidad Nacional de Colombia, Instituto Unidad de Investigaciones JurídicoSociales Gerardo Molina, 513-544

- TUVILLA-RAYO, JOSÉ (2004): Cultura de paz, Fundamentos y claves educativas, Bilbao, Ed. Desclée de Brouwer.

- UNESCO (ed) (1995): «Hacia una cultura global de paz», Presentado en el segundo foro internacional sobre la cultura de Paz, Manila. Filipinas.

\section{Mariela Sánchez Cardona}

Psicóloga, Máster Internacional en Estudios de Paz, Conflictos y Desarrollo de la Universidad Jaume I- España y a su vez está realizando el programa de Doctorado en la misma Universidad. Su línea de investigación es la Educación para la paz. Hace parte del grupo de Investigación Constitucionalismo Comparado de la Universidad Nacional de Colombia y dirige la línea de investigación de constitucionalismo y paz. Actualmente es profesora de la facultad de Psicología de la Universidad Luis Amigo en Bogotá Colombia.

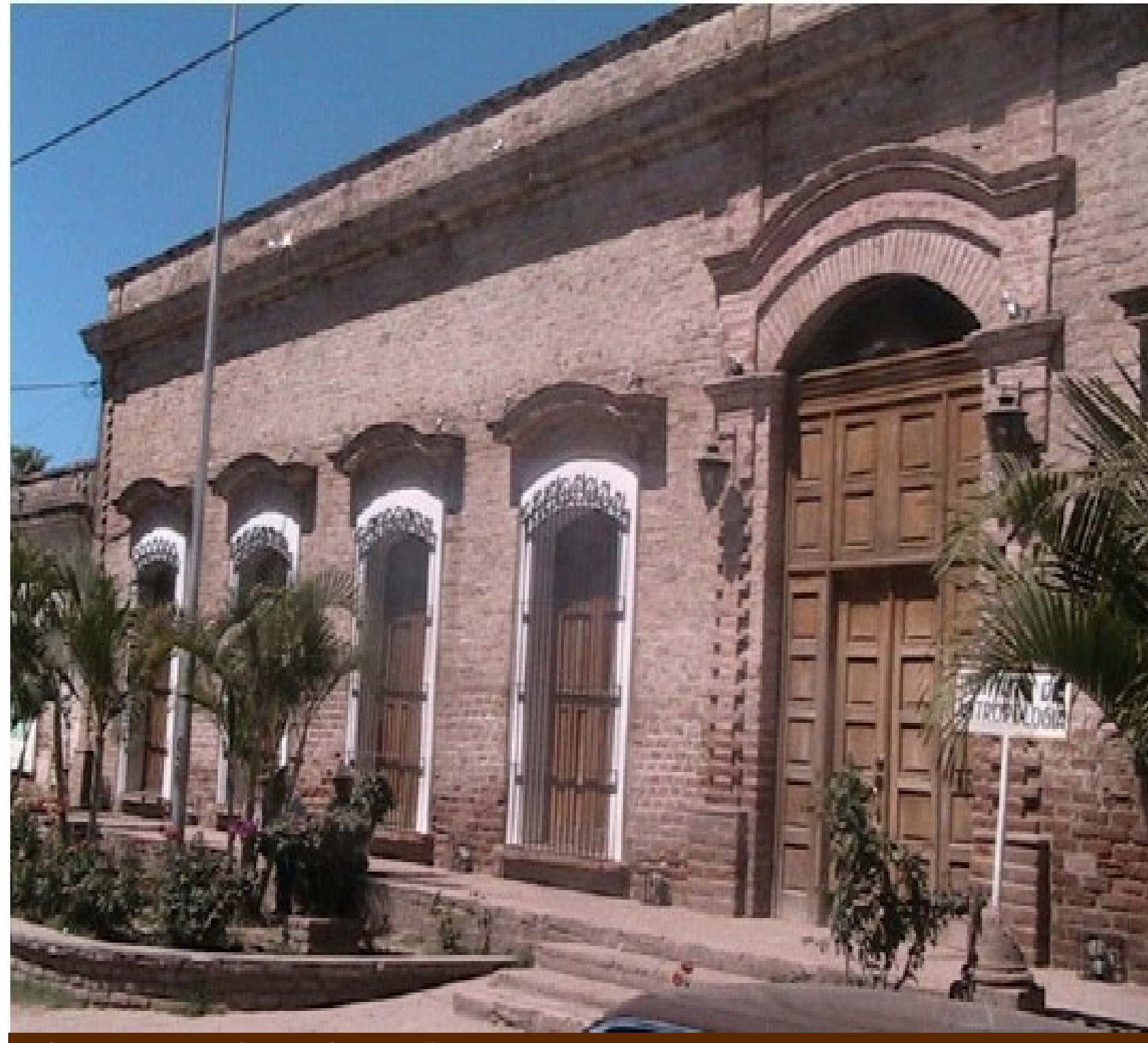

Imágen: Universidad Autónoma Indígena de México. Los Mochis 2000.
Interculturalidades 